\title{
Simulation-based education improves student self-efficacy in physiotherapy assessment and management of paediatric patients
}

\author{
Judith Hough ${ }^{1,2^{*}}$ (D), Daniel Levan ${ }^{1}$, Michael Steele ${ }^{1}$, Kristine Kelly ${ }^{3}$ and Megan Dalton ${ }^{1}$
}

\begin{abstract}
Background: The Australian Physiotherapy Council mandates that physiotherapy clinical education be sufficient to produce graduates who are competent to practice across the lifespan. Due to a lack of opportunities for paediatric clinical placements, there is a risk of graduates not having the opportunity to develop competency in paediatric physiotherapy. To address this risk, simulation-based education (SBE) has been proposed as an educational strategy to address the placement shortfall. Despite encouraging evidence for its use in physiotherapy education, there is limited evidence supporting its use specifically in paediatric populations. The aims of this research were to investigate the effect of SBE on student self-efficacy in the physiotherapy assessment and management of paediatric clients, and to determine student satisfaction with SBE as a learning strategy.
\end{abstract}

Methods: Three interactive SBE sessions were run during the undergraduate paediatric physiotherapy unit at the campus of one Australian university. Self-efficacy was surveyed before and after each session, to determine confidence in clinical skills, clinical decision-making, treatment preparation and planning, communication skills; evaluating and modifying interventions, and interprofessional practice. Student satisfaction with SBE as a learning strategy was surveyed after the final SBE session.

Results: For the 164 participants included in this study, self-efficacy survey response rate varied from 77 to $96 \%$ for each session. Significant increases in mean student self-efficacy were recorded for all questions $(p<0.001)$. A total of 139 (85\%) responded to the learning reactionnaire with $78.6 \%$ indicating they were very satisfied with SBE as a learning strategy. Written comments from 41 participants identified 'experience' as the primary theme.

Conclusion: SBE had a significant positive effect on student self-efficacy in the physiotherapy assessment and management of paediatric patients. Students also perceived SBE to be a valuable learning experience. Future research is needed to investigate whether the improvement in self-efficacy achieved through SBE translates into improved student performance during workplace-based clinical placements.

Keywords: Simulation, Paediatrics, Physiotherapy

\footnotetext{
* Correspondence: judith.hough@acu.edu.au

${ }^{1}$ School of Allied Health, Australian Catholic University, Banyo, Queensland,

Australia

${ }^{2}$ Mater Research - The University of Queensland, South Brisbane,

Queensland, Australia

Full list of author information is available at the end of the article
}

(c) The Author(s). 2019 Open Access This article is distributed under the terms of the Creative Commons Attribution 4.0 International License (http://creativecommons.org/licenses/by/4.0/), which permits unrestricted use, distribution, and reproduction in any medium, provided you give appropriate credit to the original author(s) and the source, provide a link to the Creative Commons license, and indicate if changes were made. The Creative Commons Public Domain Dedication waiver (http://creativecommons.org/publicdomain/zero/1.0/) applies to the data made available in this article, unless otherwise stated. 


\section{Background}

In physiotherapy undergraduate courses, clinical education constitutes approximately a third of the program, with students spending between 900 and $1000 \mathrm{~h}$ in supervised clinical time with patients. This professional practice component is required for program accreditation by the Australian Physiotherapy Council (APC) [1]

Clinical education relies on the availability of a diverse range of patients, however the scenarios students are exposed to, vary depending on the patients presenting during the placement [2]. Individual learning experiences vary in this model, creating learning environments which may be opportunistic, unstructured and disparate [3] Furthermore, students may get inadequate exposure to higher risk patients, resulting in missed learning opportunities [4].

In addition to these challenges, paediatric placements are limited due to a lack of suitably qualified paediatric physiotherapists to act as educators [5]. Students may therefore not have the opportunity to develop competency in paediatric physiotherapy practice prior to registration as a physiotherapist, despite the APC's requirement for development of competency across the lifespan [1].

To address the limitations of clinical education in general, and more specifically in paediatric physiotherapy education, simulation-based education (SBE) has been proposed as an additional educational strategy. SBE attempts to replicate real-life experiences through simulated scenarios, environments or patients, creating a safe environment where clinical confidence and competence can be developed $[6,7]$. With SBE, learning experiences can be tailored to specific learning objectives and can be set up on demand, eliminating the dependence on patient availability [2]. If implemented successfully, SBE can guarantee provision of consistent and diverse learning experiences and include exposure to scenarios that are clinically uncommon, promoting a more equitable learning experience for all students.

SBE has been shown to be an effective method for learning a range of physiotherapy skills, including handson [2, 8-19] and interdisciplinary skills (including teamwork and communication) [20-27]. Up to $25 \%$ of clinical placement experiences may be replaced by SBE without compromising student learning $[28,29]$. Changes to student attitudes have also been reported following SBE [30-33], including improved motivation to learn [30] and improved awareness of physiotherapy core values [32, 33]. Students have generally viewed SBE as a positive learning experience $[2,14,20,25,34-40]$ and while this does not equate to an actual learning effect, it may influence motivation to learn [41].

Improved levels of student self-efficacy have also been demonstrated with SBE [28, 29, 32, 36-40, 42, 43], where self-efficacy is defined as an individual's personal judgment in their own ability to successfully accomplish a task
[44]. Self-efficacy is a key attribute in professional practice as there is a demonstrated relationship between selfefficacy and work-related performance, such as performance in clinical environments [45].

Despite this encouraging evidence for the use of SBE in physiotherapy education, there is insufficient evidence supporting the use of SBE specifically in paediatric populations. Considering the limited clinical learning opportunities available in paediatric physiotherapy, it is important for alternative methods of education to be considered and evaluated. Therefore, the primary aim of this study was to investigate the effect of SBE on student self-efficacy in the physiotherapy assessment and management of paediatric clients. A secondary aim of this study was to determine student satisfaction with SBE as a learning strategy.

\section{Methods}

This study was a prospective, observational study using self-efficacy questionnaires and a learning reactionnaire to survey student satisfaction with $\mathrm{SBE}$ as a learning strategy.

\section{Participants}

Students studying physiotherapy at an Australian university campus were eligible for admission to the study if they were enrolled in the Paediatric Physiotherapy Practice academic unit of study which was delivered in the 3rd year of their physiotherapy program and was the final unit prior to their clinical placement year. The study was undertaken in 2014 (the first year of simulation delivery) and in the exact same format in 2018 (the most recent year to determine if there was evidence for ongoing delivery of SBE). Students who had previously attended any classes in the Paediatric Physiotherapy Practice unit (or equivalent) were excluded from the study.

Written consent was obtained prior to commencement of the first scenario. Human Research Ethics clearance was obtained through the institute HREC committee (2018-56E).

\section{Outcome measures}

The primary outcome measured in this research project was student self-efficacy in the physiotherapy assessment and management of paediatric patients. Student selfefficacy was measured using a self-efficacy questionnaire developed by Health Workforce Australia and used throughout Queensland by the Simulated Learning in Paediatric Allied Health (SLIPAH) team. This questionnaire was developed in 2010 by SLIPAH in collaboration with Clinical Skills Development Service (CSDS), a Queensland Government training provider (https://csds. qld.edu.au/). The questionnaire was designed to evaluate the efficacy of SBE against the second level (learning) of 
Kirkpatrick-Phillips' model of training evaluation, an established framework for the evaluation of training programs [46]. The second level of learning refers to changes in knowledge, skills or attitudes and is often described as a transfer of knowledge. It does not include behavioural changes or practical application resulting from these changes in knowledge, skills or attitudes [46].

Student satisfaction with SBE as a learning strategy was the secondary outcome of this project and was measured using a learning reactionnaire. This learning reactionnaire was adapted by the SLIPAH team from designs initially published by Leslie Rae [47], and was intended to establish student levels of engagement with SBE. This evaluates the first level (reaction) of Kirkpatrick-Phillip's model of training evaluation, which refers to how trainees reacted to the training [46]. Both questionnaires used a Likert 5-point rating scale, ranging from 0 (not at all confident/learning nothing) to 4 (totally confident/ learned a lot). The learning reactionnaire also gave participants the opportunity to add comments to provide additional feedback on their experience.

\section{Study procedure}

Each SBE session was designed and conducted by the SLIPAH group in consultation with university teaching staff and form part of the regular academic unit curriculum during the Paediatric Physiotherapy Practice practical classes in weeks 4,8 and 12 of a 12-week semester (Fig. 1). The scenario for each SBE session specifically targeted one of the primary clinical domains of paediatric physiotherapy and was delivered with the corresponding musculoskeletal, cardiorespiratory and neurodevelopmental modules of the unit. In the week prior to the SBE session, the students were requested to independently undertake an eLearning package to prepare them for each session (https://www.sdc.qld.edu.au/ ). The three eLearning packages suggested were on General Allied Health Paediatric Principles, Cardiorespiratory acute paediatric physiotherapy, and spina bifida and spinal disabilities.

The interactive SBE sessions used high fidelity paediatric human patient simulators which are life-like, anatomically correct, computer driven mannequins with physiologic

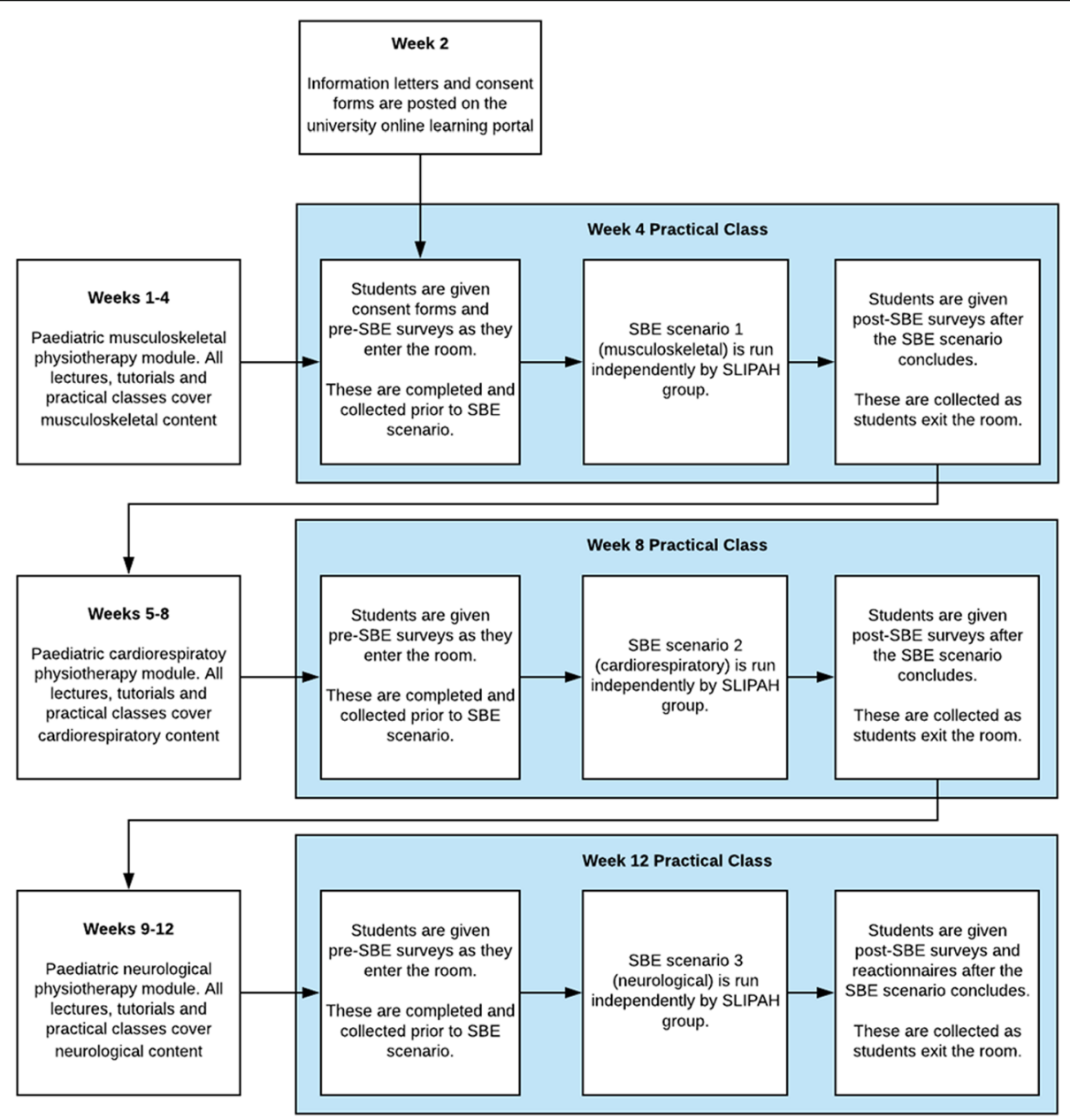

Fig. 1 Timeline of study procedure 
responses that mimic real patients. For the musculoskeletal and cardiorespiratory scenarios, the SimJunior ${ }^{\circ}$ (Laerdal Medical, Victoria, Australia) mannequin was used and for the neurodevelopmental scenario, it was Sophie Newborn $^{\bullet}$ (Laerdal Medical). Each SBE learning scenario was conducted over a two-hour period with 25 students per group. There was a 1:8 ratio of students to educators in each group.

Self-efficacy questionnaires were completed by participants in the first $5 \mathrm{~min}$ of each session and were collected prior to commencement of the scenario. A second, identical questionnaire was given to each participant at the completion of the SBE scenario. At the completion of the third and final SBE session the learning reactionnaire was also given to participants and collected as students left the session. All questionnaires were given in paper format.

\section{Statistical analysis}

To analyse the pre-post differences in self-efficacy for each of the three scenarios, a Wilcoxon Signed Ranks Test and a descriptive statistics report was undertaken using IBM SPSS Version 25 (IBM Corp, Armonk, NY, USA). A Kruskal Wallis test was used to determine if there were any differences between the 3 scenarios at baseline. A $p$-value of 0.05 was considered significant.

To report student satisfaction with SBE, descriptive statistics were used to report on quantitative data and a thematic analysis with Leximancer software Leximancer (Leximancer Pty Ltd., Brisbane, Australia) was used to report qualitative data.

\section{Results}

From the cohort of ninety-two (92) students enrolled in the Paediatric Physiotherapy Practice unit in 2018, 1 student was excluded due to previous enrolment and 1 student declined to participate. Seventy-four (74) students were enrolled in the Paediatric Physiotherapy Practice unit in 2014. Questionnaire response rates for each of the three SBE scenarios and learning reactionnaire are in Table 1.

Table 1 Response rates to the learning reactionnaire and questionnaire for each of the three simulation-based education scenarios

\begin{tabular}{lll}
\hline & 2014 & 2018 \\
& $N(\%)$ & $N(\%)$ \\
\hline Total enrolled & 74 & 92 \\
Scenario 1 - Musculoskeletal & $70(95)$ & $86(96)$ \\
Scenario 2 - Cardiorespiratory & $67(91)$ & $82(91)$ \\
Scenario 3 - Neurological & $57(77)$ & $77(86)$ \\
Learning Reactionnaire & $62(84)$ & $77(86)$ \\
\hline
\end{tabular}

\section{Self-efficacy}

Significant increases in mean student self-efficacy were recorded for all questions in each scenario $(p<0.001)$ with improvements in mean self-efficacy scores ranging from 0.73-0.97 for all questions across all scenarios (Tables 2, 3, 4). Question 2 (clinical decision-making) had the largest mean improvement to self-efficacy in 2 out of the 3 scenarios (musculoskeletal and cardiorespiratory) as well as the largest mean improvement overall (0.93), while question 4 (maintaining communication with nurse, carer and child) had the lowest mean improvement in 2 out of the 3 scenarios (musculoskeletal and cardiorespiratory) as well as the lowest mean improvement overall (0.77). Questions 4 and 7 had the highest pre and post SBE scores in all 3 scenarios, and respectively had the highest pre $(1.99,1.91)$ and post $(2.76,2.72)$ scores overall. Question 2 had the lowest pre and post SBE scores in every scenario and overall (pre = 1.48 , post $=2.41$ ).

In every question, participants who reported an increase in self-efficacy post SBE (positive ranks) outnumbered participants who reported a decrease (negative ranks) or no change (ties). For all questions across all scenarios: positive ranks ranged from $62.8-80.8 \%$ of respondents; negative ranks ranged from 0 to $2.6 \%$ of respondents; and ties ranged from $19.2-34.6 \%$ of respondents. (Figure 2) Question 1 (preparation for treating paediatric patients) and Question 2 (clinical decision-making) had the highest number of positive ranks recorded in 2 out of the 3 scenarios (musculoskeletal and cardiorespiratory), while Question 4 (maintaining communication) had the highest number of negative ranks and ties in 2 out of the 3 scenarios (cardiorespiratory and neurological). Question 4 also had the highest number of total negative ranks [9] and ties (147) recorded across all scenarios (Table 5).

Analysis of the pre self-efficacy scores between the three scenarios showed no significant differences $(p>$ $0.07)$.

\section{Student satisfaction with SBE as a learning strategy}

There was a total of 139 responses to the learning reactionnaire, $62(83.8 \%)$ in 2014 and $77(85.6 \%)$ in 2018 (Table 6). Most student responses (78.6\%) indicated that the SBE scenarios were an effective model for promoting learning in the field of paediatric physiotherapy. Mean responses ranged from 2.76 to 3.12 for all questions. The mean rating for Question 2 (promotion of self-directed learning) of 2.76 was substantially lower than the other questions, which ranged from 3.01-3.12, For the entire questionnaire, there was only 1 response with a rating of $0(0.1 \%)$ and 14 recorded ratings of 1 (1.7\%). 
Table 2 Change in self-efficacy after SBE scenario 1 (musculoskeletal) for combined 2014 and 2018 cohort, where $0=$ "not at all", 1 = "a little", 2 = "moderately", 3 = "a lot" and 4 = "totally" confident

\begin{tabular}{lllllllll}
\hline Question & Mean Pre Score & Mean Post Score & Mean Difference & P-Value & Negative Ranks & Positive Ranks & Ties & Total \\
\hline Q1 & $1.54 \pm 0.57$ & $2.48 \pm 0.62$ & 0.94 & $<0.001$ & $0(0 \%)$ & $126(80.8 \%)$ & $30(19.2 \%)$ & 156 \\
Q2 & $1.48 \pm 0.61$ & $2.45 \pm 0.66$ & 0.97 & $<0.001$ & $1(0.6 \%)$ & $122(78.7 \%)$ & $32(20.6 \%)$ & 155 \\
Q3 & $1.71 \pm 0.65$ & $2.66 \pm 0.62$ & 0.95 & $<0.001$ & $1(0.6 \%)$ & $116(74.8 \%)$ & $38(24.5 \%)$ & 155 \\
Q4 & $2.04 \pm 0.72$ & $2.77 \pm 0.71$ & 0.73 & $<0.001$ & $4(2.6 \%)$ & $99(63.5 \%)$ & $53(34 \%)$ & 156 \\
Q5 & $1.67 \pm 0.69$ & $2.54 \pm 0.62$ & 0.86 & $<0.001$ & $3(1.9 \%)$ & $109(69.9 \%)$ & $44(28.2 \%)$ & 156 \\
Q6 & $1.56 \pm 0.70$ & $2.48 \pm 0.61$ & 0.92 & $<0.001$ & $2(1.3 \%)$ & $118(75.6 \%)$ & $36(23.1 \%)$ & 156 \\
Q7 & $2.01 \pm 0.76$ & $2.78 \pm 0.66$ & 0.76 & $<0.001$ & $4(2.6 \%)$ & $98(62.8 \%)$ & $54(34.6 \%)$ & 156 \\
\hline
\end{tabular}

Of the 62 learning reactionnaire responses submitted in 2014, there were 20 (32.3\%) written comments, and for the 77 in 2018, there were $21(27.3 \%)$ written comments. The primary theme identified was experience (reported in 13 (32\%) comments) and was mentioned alongside the concepts of skills, practical, helped, information, and simulated (Fig. 3). Some examples of responses submitted included 'Good experience + practical skills; Awesome learning experience!; They helped to put theory into practice and increase knowledge, understanding and practical skills; Very hands on and practical; The simulated classes were very helpful and helped with retention of information; Really good team, able to teach all the information effectively in a form that will be retained!; I like the handling skills we learnt and how to talk to other people in the team and the family."

Other themes mentioned included learning [7], thank [5], need and groups [3], and love [2], with responses such as 'Fantastic module! Love this style of learning; Thank you! It was a Great learning environment; Working in small groups with dolls was very beneficial; Love this way of teaching. It's more real world.

\section{Discussion}

Significant improvements in student self-efficacy in the physiotherapy assessment and management of paediatric clients was found with SBE, demonstrating that students felt improved confidence in clinical skills, clinical decision- making, treatment preparation and planning, communication skills, evaluating and modifying interventions and interprofessional practice. These improvements mirror previous research conducted in an adult physiotherapy context [36, 37, 42].

Students showed the largest improvements in Question 2, indicating that students perceived the greatest improvements to their clinical decision-making skills. Interestingly, this question had the lowest pre and post SBE scores in all scenarios, demonstrating that despite the improvement, students remained least confident in their clinical decision-making skills. Students have had limited opportunities to refine their clinical decisionmaking skills at this stage of their learning, which is a possible explanation for their lower initial levels of confidence. Given this lack of experience, it is reasonable that a small amount of experience (such as a single SBE session) would be sufficient to cause a significant increase in confidence.

Conversely, Questions 4 and 7 had the highest pre and post SBE scores, while having the smallest overall improvements in self-efficacy. Students were most confident in their communication and inter professional skills and perceived the least amount of improvements to these skills. Previous research has also shown students to have higher levels of confidence in their communication skills compared to their confidence in treatment and hazard awareness [43]. It is likely that students were more

Table 3 Change in self-efficacy after SBE scenario 2 (cardiorespiratory) for combined 2014 and 2018 cohort, where $0=$ "not at all", $1=$ "a little", 2 = "moderately", 3 = "a lot" and 4 = "totally" confident

\begin{tabular}{lllllllll}
\hline Question & Mean Pre Score & Mean Post Score & Mean Difference & P-Value & Negative Ranks & Positive Ranks & Ties & Total \\
\hline Q1 & $1.55 \pm 0.61$ & $2.43 \pm 0.63$ & 0.88 & $<0.001$ & $1(0.7 \%)$ & $110(73.8 \%)$ & $38(25.5 \%)$ & 149 \\
Q2 & $1.49 \pm 0.61$ & $2.38 \pm 0.65$ & 0.89 & $<0.001$ & $2(1.3 \%)$ & $107(71.8 \%)$ & $40(26.8 \%)$ & 149 \\
Q3 & $1.67 \pm 0.64$ & $2.52 \pm 0.62$ & 0.85 & $<0.001$ & $2(1.4 \%)$ & $107(72.3 \%)$ & $39(26.4 \%)$ & 148 \\
Q4 & $1.98 \pm 0.72$ & $2.76 \pm 0.67$ & 0.78 & $<0.001$ & $3(2 \%)$ & $97(65.1 \%)$ & $49(32.9 \%)$ & 149 \\
Q5 & $1.60 \pm 0.63$ & $2.45 \pm 0.67$ & 0.85 & $<0.001$ & $0(0 \%)$ & $107(71.8 \%)$ & $42(28.2 \%)$ & 149 \\
Q6 & $1.58 \pm 0.63$ & $2.40 \pm 0.69$ & 0.81 & $<0.001$ & $3(2 \%)$ & $102(68.5 \%)$ & $44(29.5 \%)$ & 149 \\
Q7 & $1.85 \pm 0.70$ & $2.71 \pm 0.64$ & 0.86 & $<0.001$ & $0(0 \%)$ & $104(69.8 \%)$ & $45(30.2 \%)$ & 149 \\
\hline
\end{tabular}


Table 4 Change in self-efficacy after SBE scenario 3 (neurological) for combined 2014 and 2018 cohort, where $0=$ "not at all", $1=$ "a little", 2 = "moderately", 3 = "a lot" and 4 = "totally" confident

\begin{tabular}{lllllllll}
\hline Question & Mean Pre Score & Mean Post Score & Mean Difference & P-Value & Negative Ranks & Positive Ranks & Ties & Total \\
\hline Q1 & $1.55 \pm 0.58$ & $2.41 \pm 0.66$ & 0.86 & $<0.001$ & $2(1.5 \%)$ & $98(73.1 \%)$ & $34(25.4 \%)$ & 134 \\
Q2 & $1.47 \pm 0.61$ & $2.40 \pm 0.65$ & 0.93 & $<0.001$ & $2(1.5 \%)$ & $101(75.4 \%)$ & $31(23.1 \%)$ & 134 \\
Q3 & $1.67 \pm 0.64$ & $2.56 \pm 0.63$ & 0.89 & $<0.001$ & $1(0.7 \%)$ & $96(71.6 \%)$ & $37(27.6 \%)$ & 134 \\
Q4 & $1.96 \pm 0.67$ & $2.74 \pm 0.68$ & 0.79 & $<0.001$ & $3(2.2 \%)$ & $86(64.2 \%)$ & $45(33.6 \%)$ & 134 \\
Q5 & $1.67 \pm 0.56$ & $2.44 \pm 0.61$ & 0.77 & $<0.001$ & $1(0.8 \%)$ & $90(68.7 \%)$ & $40(30.5 \%)$ & 131 \\
Q6 & $1.56 \pm 0.62$ & $2.51 \pm 0.73$ & 0.95 & $<0.001$ & $2(1.5 \%)$ & $100(74.6 \%)$ & $32(23.9 \%)$ & 134 \\
Q7 & $1.86 \pm 0.67$ & $2.67 \pm 0.68$ & 0.81 & $<0.001$ & $1(0.7 \%)$ & $92(68.7 \%)$ & $41(30.6 \%)$ & 134 \\
\hline
\end{tabular}

a)

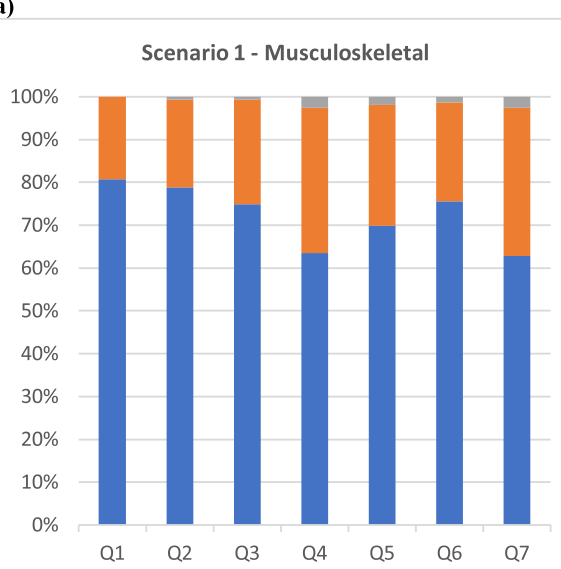

- Increase to SE No Change to SE Decrease to SE

c)
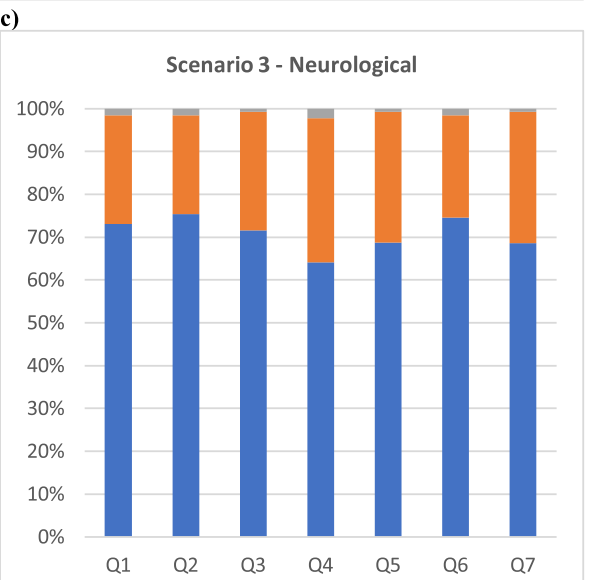

- Increase to SE $\quad$ No Change to SE $\square$ Decrease to SE b)

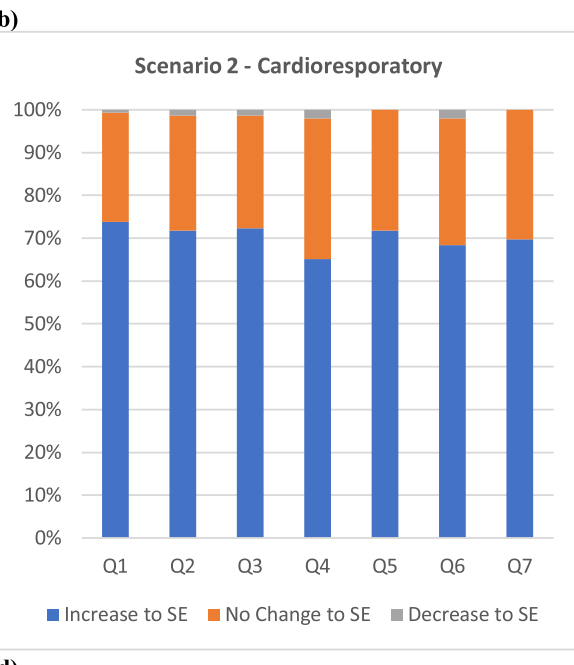

d)

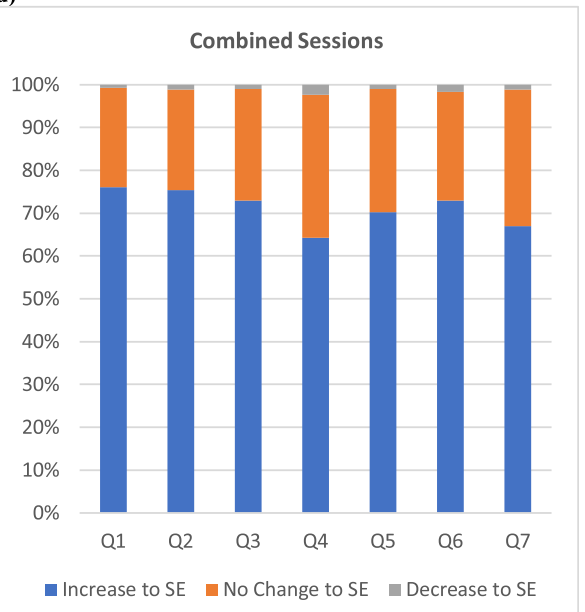

Fig. 2 Percentage of students who had an increase, decrease or no change to self-efficacy (SE) for each session. a shows results for the first (musculoskeletal) scenario. b shows results for the second (cardiorespiratory) scenario. c shows results for the third (neurological) scenario. d shows results for all scenarios combined 
Table 5 Change in self-efficacy for all sessions combined, where 0 = "not at all", 1 = "a little", 2 = "moderately", 3 = "a lot" and 4 = "totally" confident

\begin{tabular}{|c|c|c|c|c|c|c|c|c|c|}
\hline Question & Mean Pre Score & Mean Post Score & Post scores $\geq 3$ & Mean Difference & $P$-Value & Negative Ranks & Positive Ranks & Ties & Total \\
\hline Q1 & $1.55 \pm 0.59$ & $2.45 \pm 0.63$ & $196(44.6 \%)$ & 0.90 & $<0.001$ & $3(0.7 \%)$ & 334 (76.1\%) & $102(23.2 \%)$ & 439 \\
\hline Q2 & $1.48 \pm 0.61$ & $2.41 \pm 0.65$ & $192(43.8 \%)$ & 0.93 & $<0.001$ & $5(1.1 \%)$ & $330(75.3 \%)$ & $103(23.5 \%)$ & 438 \\
\hline Q3 & $1.68 \pm 0.64$ & $2.58 \pm 0.62$ & 240 (54.9\%) & 0.90 & $<0.001$ & $4(0.9 \%)$ & $319(73 \%)$ & $114(26.1 \%)$ & 437 \\
\hline Q4 & $1.99 \pm 0.71$ & $2.76 \pm 0.69$ & $293(66.7 \%)$ & 0.77 & $<0.001$ & $10(2.3 \%)$ & $282(64.2 \%)$ & 147 (33.5\%) & 439 \\
\hline Q5 & $1.65 \pm 0.64$ & $2.48 \pm 0.63$ & 195 (44.7\%) & 0.83 & $<0.001$ & $4(0.9 \%)$ & $306(70.2 \%)$ & $126(28.9 \%)$ & 436 \\
\hline Q6 & $1.57 \pm 0.65$ & $2.46 \pm 0.68$ & 204 (46.5\%) & 0.89 & $<0.001$ & $7(1.6 \%)$ & $320(72.9 \%)$ & 112 (25.5\%) & 439 \\
\hline Q7 & $1.91 \pm 0.72$ & $2.72 \pm 0.66$ & 277 (63.1\%) & 0.81 & $<0.001$ & $5(1.1 \%)$ & $294(67 \%)$ & 140 (31.9\%) & 439 \\
\hline
\end{tabular}

confident with their communication and interpersonal skills prior to SBE as they have had the more opportunities to develop these skills throughout the early years of their program of study. Furthermore, it is possible that additional learning experiences may be required to realise changes in these more well-developed skills. It is also possible that these smaller improvements to communication and interpersonal skills can be explained by a ceiling effect, given students' higher initial levels of confidence.

A lack of confidence working with children has been reported to be a barrier to graduates seeking employment in paediatric physiotherapy, and evidence suggests confidence in graduate paediatric physiotherapists is directly related to competence in communication skills [48]. Therefore, confidence in communication is particularly important for graduates seeking employment as a paediatric physiotherapist. Although the questions relating to communication skills [4, 7] had the smallest improvements in self-efficacy, they were still statistically significant and the majority of students (64.9\%) reported scores of 3 or higher after SBE, indicating that they had at least "a lot" of confidence in their communication and inter professional skills. It seems that SBE has provided a level of confidence in communication skills which may aid reduction of the barriers to working in a paediatric context.

Although self-efficacy improved from the start to the end of each SBE scenario, there was no improvement in pre self-efficacy scores over the course of the entire academic unit. At the start of each new SBE scenario, self-efficacy scores returned to baseline levels. As previously described by Wright et al. (43), this suggests that students' self-efficacy is linked to area-specific knowledge and skills and does not necessarily transfer between areas. It is not a function of simulation, but the specific clinical knowledge and skills gained during the process.

\section{Student satisfaction with SBE}

The secondary aim of this research project was to determine student satisfaction with SBE as a learning strategy. The response was positive, with most students considering that SBE met their style of learning, promoted self-directed learning, delivered evidence-based principles of paediatric physiotherapy, assisted in retention of paediatric physiotherapy, provided an ideal learning environment, and provided incentive for further skill development in paediatric physiotherapy. Only one student $(0.7 \%)$ thought that SBE provided no incentive at all for further skill development in paediatric physiotherapy. These findings are consistent with two systematic reviews, which concluded that SBE is generally well received by students and an experience valuable to learning $[2,16]$. The positive findings observed in the quantitative results were reflected by students' comments. The thematic analysis identified. that students found SBE to be a beneficial and enjoyable learning experience.

Table 6 Summary of learning reactionnaire responses for combined 2014 and 2018 cohort

\begin{tabular}{|c|c|c|c|c|c|c|c|c|}
\hline Question & Score 0 (Not at all) & Score 1 (A little) & Score 2 (Moderately) & Score 3 (A lot) & Score 4 (Totally) & Range & Mean & Total \\
\hline$\overline{Q 1}$ & $0(0 \%)$ & $1(0.7 \%)$ & $27(19.6 \%)$ & 80 (58\%) & $30(21.7 \%)$ & 3 & $3.01 \pm 0.67$ & 138 \\
\hline Q2 & $0(0 \%)$ & $7(5.1 \%)$ & $38(27.5 \%)$ & $74(53.6 \%)$ & $19(13.8 \%)$ & 3 & $2.76 \pm 0.75$ & 138 \\
\hline Q3 & $0(0 \%)$ & $1(0.7 \%)$ & $27(19.6 \%)$ & $64(46.4 \%)$ & $46(33.3 \%)$ & 3 & $3.12 \pm 0.74$ & 138 \\
\hline Q4 & $0(0 \%)$ & $2(1.5 \%)$ & $26(19 \%)$ & $75.5(55.1 \%)^{\mathrm{a}}$ & $34.5(25.2 \%)^{a}$ & 3 & $3.03 \pm 0.71$ & 137 \\
\hline Q5 & $0(0 \%)$ & $2(1.5 \%)$ & $22(16.1 \%)$ & $72(52.6 \%)$ & $41(29.9 \%)$ & 3 & $3.11 \pm 0.71$ & 137 \\
\hline Q6 & $1(0.7 \%)$ & $1(0.7 \%)$ & $23(16.7 \%)$ & $74(53.6 \%)$ & $39(28.3 \%)$ & 4 & $3.08 \pm 0.74$ & 138 \\
\hline Total & $1(0.1 \%)$ & $14(1.7 \%)$ & $163(19.7 \%)$ & 439.5 (53.1\%) & $209.5(25.3 \%)$ & 4 & $3.02 \pm 0.73$ & 827 \\
\hline
\end{tabular}

${ }^{\mathrm{a}} 1$ participant submitted a score of 3.5 for question 4 


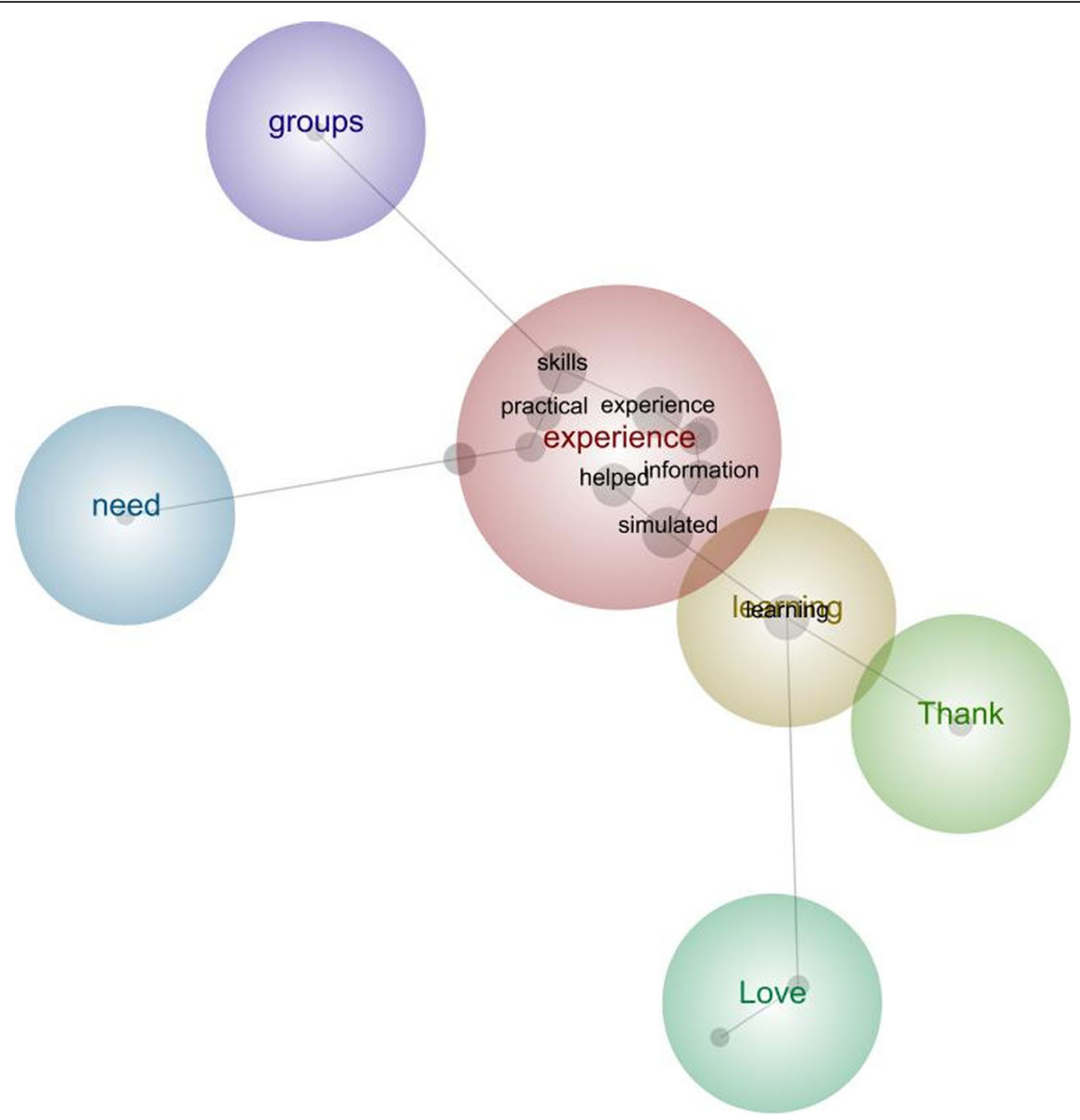

Fig. 3 Leximancer concept map illustrating the main concepts identified by the students in the learning reactionnaire and how they interrelate with each other

The mean rating for Question 2 (promotion of selfdirected learning) of 2.76 was substantially lower than the other questions, and again may reflect the structure of the SBE scenarios and/or insufficient emphasis on self-directed learning activities.

Overall, the student response to SBE was positive, and if students respond well to this method of learning, it could suggest they are more likely to be engaged with the learning experience and be more motivated to learn [41].

\section{Translation to performance}

While the improvements to self-efficacy observed in this study are significant, these improvements may not translate to an improved level of workplace-based clinical performance. The self-efficacy questionnaires provide a measure of perceived confidence in students' knowledge, skills and attitudes, demonstrating that they have achieved a degree of learning, according to the Kirkpatrick-Phillips' model of training evaluation [46]. The questionnaires give no indication whether participants have applied what they've learned through changes in behaviour, the next tier in the Kirkpatrick-Phillips' model [46]. There are wellestablished links between self-efficacy and work-related performance [45] so it is reasonable to suggest that students who demonstrated improvements in self-efficacy following SBE would have improved performance following SBE. Previously, SBE has led to significant improvements in student performance, $[28,43]$ improved patient care and better patient outcomes, [49] strengthening the suggestion that these improvements to self-efficacy may translate to improved performance with real patients. However, students who receive SBE also may be more likely to overestimate their ability [50] and are likely to be less realistic in their self-evaluation in a simulated environment [32]. Therefore translation to improved performance should not be assumed based on these selfreported measures alone.

To measure performance, student behaviour would need to be evaluated in a standardised or clinical 
environment. There are established instruments for measuring performance, such as the validated Assessment of Physiotherapy Performance (APP) [51] or the Physical Therapy Clinical Performance Instrument (PT CPI) [52]. The APP is currently used by Australian universities to evaluate the performance of students on clinical placement and has been used in other studies examining the efficacy of SBE [28, 29, 43, 50, 53]. In two previous studies, students who participated in SBE achieved superior grades, measured through their performance in the APP $[28,43]$. It would be beneficial to conduct a follow-up study to determine if there are similar differences in student performance for this student group.

\section{Limitations}

Although clear improvements to student self-efficacy following SBE were observed in this study, there is no comparison to standard educational methods. Without this comparison, it is not possible to determine whether the educational benefit gained from SBE differs from standard curriculum. This is especially important given the high cost of SBE, which is often a barrier to its implementation [54].

Students completed their self-efficacy questionnaires immediately after the SBE scenarios ended, meaning that the results only reflect the short-term effect of SBE. Although some students commented that they felt SBE improved their retention of paediatric physiotherapy, without further investigation it is not possible to determine if SBE had any long-lasting effects. There is also no measure on actual student performance.

By comparing APP results of paediatric placements, we could investigate if there is any difference between the performance of students who participated in SBE and those who received standard curriculum, as well as gain information on the long-term effects of SBE, as clinical placements occur months after the SBE ends.

There is no information on whether SBE changed students desire to work in paediatric physiotherapy in the future. Results from learning reactionnaire Question 6 (incentive to develop skills further in paediatric physiotherapy) offers some support for this, with $82 \%$ responses recorded as "a lot" or "totally", demonstrating that students had incentive to further develop paediatric physiotherapy skills following SBE. However, this does not mean students would pursue paediatric physiotherapy opportunities. To get a better indication of this, it would be beneficial to ask students if SBE has increased the likelihood of them pursuing a career in paediatric physiotherapy or requesting a paediatric placement in future research in this area.

Only undergraduate university students were included in this study, so results should not be extrapolated and applied to other populations such as junior, employed physiotherapists. Furthermore, participants were all from one campus of one Australian university and may not accurately represent students of other campuses or Australian universities.

\section{Conclusion}

The results of the self-efficacy questionnaire were clearly positive, with significant improvements to student selfefficacy post SBE recorded for every question, indicating that SBE has a positive effect on student self-efficacy in the physiotherapy assessment and management of paediatric clients. Students also reported that they found SBE to be a valuable learning experience.

\section{Abbreviations \\ ACU: Australian Catholic University; APC: Australian Physiotherapy Council; APP: Assessment of Physiotherapy Performance; CSDS: Clinical Skills Development Service; HREC: Human Research Ethics Committee; PT CPI: Physical Therapy Clinical Performance Instrument; SBE: Simulation-based education; SE: Self-efficacy; SLIPAH: Simulated Learning in Paediatric Allied Health}

\section{Acknowledgements}

The authors would also like to acknowledge the SLIPAH team for developing the questionnaires and accommodating researchers in the SBE sessions.

\section{Authors' contributions}

All authors ( $\mathrm{H}, \mathrm{DL}, \mathrm{MS}, \mathrm{KK}, \mathrm{MD})$ participated in the data analysis and in the development and revision of the manuscript. In addition, DL conducted the data collection. All authors have read and approved the final version of the manuscript.

\section{Funding}

There was no funding received for this research project.

\section{Availability of data and materials}

The datasets used and/or analysed during the current study are available from the corresponding author on reasonable request.

Ethics approval and consent to participate

Ethical clearance was obtained through the ACU Human Research Ethics Committee (ACU HREC). Ethics Register Number: 2018-56E. Written consent was received for all participants through physical consent forms prior to research commencement.

Consent for publication

Not applicable.

Competing interests

The authors declare that they have no competing interests.

\section{Author details}

${ }^{1}$ School of Allied Health, Australian Catholic University, Banyo, Queensland, Australia. ${ }^{2}$ Mater Research - The University of Queensland, South Brisbane, Queensland, Australia. ${ }^{3}$ Office of the Executive Director of Allied Health, South Brisbane, Queensland, Australia.

Received: 14 July 2019 Accepted: 27 November 2019 Published online: 16 December 2019

\section{References}

1. Australian Physiotherapy Council. Accreditation Standard for Physiotherapy Practitioner Programs December 2016 [cited 2017 14/05/2017]. Available from: https://physiocouncil.com.au/media/1241/accreditation-standardfinal-16122016.pdf. 
2. Pritchard SA, Blackstock FC, Nestel D, Keating JL. Simulated patients in physical therapy education: systematic review and meta-analysis. Phys Ther. 2016;96(9):1342-53.

3. Weller JM, Nestel D, Marshall SD, Brooks PM, Conn JJ. Simulation in clinical teaching and learning. Med J Aust. 2012;196(9):594.

4. Blackstock FC, Jull GA. High-fidelity patient simulation in physiotherapy education. Aust J Physiother. 2007;53(1):3-5.

5. Queensland Physiotherapy Placement Collaborative. Queensland physiotherapy placement Collaborative - clinical network reports (20092016). Brisbane: Queensland Health; 2016.

6. Clerihew L, Rowney D, Ker J. Simulation in paediatric training. Arch Dis Child Educ Pract Ed. 2016;101(1):8-14.

7. Ryall T, Judd BK, Gordon CJ. Simulation-based assessments in health professional education: a systematic review. J Multidiscip Healthc. 2016; 9:69-82.

8. Anson E, Cook C, Camacho C, Gwilliam B, Karakostas T. The use of an educational model in the improvement of student reliability in finding R1. J Man Manipulative Ther. 2003;11(4):204-12.

9. Chang JY, Chang GL, Chien CJC, Chung KC, Hsu AT. Effectiveness of two forms of feedback on training of a joint mobilization skill by using a joint translation simulator. Phys Ther. 2007;87(4):418-30.

10. Gann N, Rogers C, Dudley A. A comparison of physical therapy students with and without instructions in ultrasound pressure application. J Allied Health. 2002;31(2):103-5.

11. Hassam M, Williams M. Education via simulation: teaching safe chest percussion for pre-term infants. Hong Kong Physiother J. 2003;21:22-8.

12. Hewson K, Friel K. A unique preclinical experience: concurrent mock and pro bono clinics to enhance student readiness. J Phys Ther Educ. 2004;18(1):80-6.

13. Hila J, Ellis E, Holmes W. Feedback withdrawal and changing compliance during manual hyperinflation. Physiother Res Int. 2002;7(2):53-64.

14. Keim Janssen SA, VanderMeulen SP, Shostrom VK, Lomneth CS. Enhancement of anatomical learning and developing clinical competence of first-year medical and allied health profession students. Anat Sci Educ. 2014;7(3):181-90.

15. Lee M, Moseley A, Refshauge K. Effect of feedback on learning a vertebral joint mobilization skill. Phys Ther. 1990;70(2):97-102.

16. Mori B, Carnahan H, Herold J. Use of simulation learning experiences in physical therapy entry-to-practice curricula: a systematic review. Physiother Can. 2015;67(2):194-202

17. Sanders BR, Ruvolo JF. Mock clinic. An approach to clinical education. Phys Ther. 1981;61(8):1163-7.

18. Snodgrass SJ, Odelli RA. Objective concurrent feedback on force parameters improves performance of lumbar mobilisation, but skill retention declines rapidly. Physiother. 2011;98(1):47-56

19. van Zoest GGJM, Staes FFGM, Stappaerts KH. Three-dimensional manual contact force evaluation of graded perpendicular push force delivery by second-year physiotherapy students during simple feedback training. J Manip Physiol Ther. 2007;30(6):438-49.

20. Buckley S, Hensman M, Thomas S, Dudley R, Nevin G, Coleman J. Developing interprofessional simulation in the undergraduate setting: experience with five different professional groups. J Interprof Care. 2012 26(5):362-9.

21. King J, Beanlands S, Fiset V, Chartrand L, Clarke S, Findlay T, et al. Using interprofessional simulation to improve collaborative competences for nursing, physiotherapy, and respiratory therapy students. J Interprof Care. 2016:30(5):599-605.

22. Rossler KL, Kimble LP. Capturing readiness to learn and collaboration as explored with an interprofessional simulation scenario: a mixed-methods research study. Nurse Educ Today. 2016;36:348-53.

23. Seefeldt TM, Mort JR, Brockevelt B, Giger J, Jordre B, Lawler M, et al. A pilot study of interprofessional case discussions for health professions students using the virtual world second life. Curr Pharm Teach Learn. 2012;4(4):224-31.

24. Shoemaker MJ, de Voest M, Booth A, Meny L, Victor J. A virtual patient educational activity to improve interprofessional competencies: a randomized trial. J Interprof Care. 2015;29(4):395-7.

25. Shoemaker MJ, Platko CM, Cleghorn SM, Booth A. Virtual patient care: an interprofessional education approach for physician assistant, physical therapy and occupational therapy students. J Interprof Care. 2014;28(4): 365-7.
26. Solomon P, Salfi J. Evaluation of an interprofessional education communication skills initiative. Educ Health. 2011;24(2):10p.

27. Wamsley M, Staves J, Kroon L, Topp K, Hossaini M, Newlin B, et al. The impact of an interprofessional standardized patient exercise on attitudes toward working in interprofessional teams. J Interprof Care. 2012;26(1): 28-35.

28. Blackstock FC, Watson KM, Morris NR, Jones A, Wright A, McMeeken JM, et al. Simulation can contribute a part of cardiorespiratory physiotherapy clinical education: two randomized trials. Simul Healthc. 2013;8(1):32-42.

29. Watson K, Wright A, Morris N, McMeeken J, Rivett D, Blackstock F, et al. Can simulation replace part of clinical time? Two parallel randomised controlled trials. Med Educ. 2012;46(7):657-67.

30. Dennis D, Furness A, Parry S. Challenging conversations with simulated patients. Clin Teach. 2017;14(6):397-400.

31. Hale LS, Lewis DK, Eckert RM, Wilson CM, Smith BS. Standardized patients and multidisciplinary classroom instruction for physical therapist students to improve interviewing skills and attitudes about diabetes. J Phys Ther Educ. 2006;20(1):22-7.

32. Hayward LM, Blackmer B. A model for teaching and assessing core values development in doctor of physical therapy students. J Phys Ther Educ. 2010;24(3):16-26.

33. Hayward LM, Blackmer B, Markowski A. Standardized patients and communities of practice: a realistic strategy for integrating the core values in a physical therapist education program. J Phys Ther Educ. 2006;20(2):29-37.

34. Bishop KL, Sharp J, Ohtake PJ. A hybrid simulation-based pre-professional physical therapist intensive care unit course. J Acute Care Phys Ther. 2017; 8(2):65-75.

35. Giesbrecht EM, Wener PF, Pereira GM. A mixed methods study of student perceptions of using standardized patients for learning and evaluation. Adv Med Educ Pract. 2014;5:241-55.

36. Mandrusiak AM, Isles R, Chang AT, Choy NLL, Toppenberg R, McCook D, et al. Senior physiotherapy students as standardised patients for junior students enhances self-efficacy and satisfaction in both junior and senior students. BMC Med Educ. 2014;14(1):105.

37. Ohtake PJ, Lazarus M, Schillo R, Rosen M. Simulation experience enhances physical therapist student confidence in managing a patient in the critical care environment. Phys Ther. 2013:93(2):216-28.

38. Shoemaker MJ, Riemersma L, Perkins R. Use of high fidelity human simulation to teach physical therapist decision-making skills for the intensive care setting. Cardiopulm Phys Ther J. 2009;20(1):13-8.

39. Silberman NJ, Panzarella KJ, Melzer BA. Using human simulation to prepare physical therapy students for acute care clinical practice. J Allied Health. 2013;42(1):25-32.

40. Smith BM, Scherer BS, Jones BL, Weis-Rodriguez BJ. An intensive care unit simulation for patients with neurologic disorders. Neurol Rep. 1996;20(1):47-50

41. Kirkpatrick DL. Evaluating training programs : the four levels. 2nd ed. San Francisco, Calif.: San Francisco, Calif. : Berrett-Koehler Publishers; 1998.

42. Nithman RW, Spiegel JJ, Lorello D. Effect of high-fidelity ICU simulation on a physical therapy student's perceived readiness for clinical education. J Acute Care Phys Ther. 2016;7(1):16-24.

43. Wright A, Moss P, Dennis DM, Harrold M, Levy S, Furness AL, et al. The influence of a full-time, immersive simulation-based clinical placement on physiotherapy student confidence during the transition to clinical practice. Adv Simul. 2018;3:3

44. Gallagher MW. Self-Efficacy. In: Ramachandran VS, editor. Encyclopedia of Human Behavior. 2nd ed. Burlington: Elsevier; 2012.

45. Stajkovic AD, Luthans F. Self-efficacy and work-related performance: a metaanalysis. Psychol Bull. 1998;124(2):240-61.

46. Phillips JJ. Return on investment in training and performance improvement programs. London: Routledge; 2012.

47. Rae L. Using Evaluation in Training and Development. 1st edition, London: Kogan Page; 1999

48. Black LL, Jensen GM, Mostrom E, Perkins J, Ritzline PD, Hayward L, et al. The first year of practice: an investigation of the professional learning and development of promising novice physical therapists. (research report). Phys Ther. 2010;90(12):1758-73.

49. McGaghie WC, Issenberg SB, Cohen ER, Barsuk JH, Wayne DB. Does simulation-based medical education with deliberate practice yield better results than traditional clinical education? A meta-analytic comparative review of the evidence. Acad Med. 2011;86(6):706-11. 
50. Jones A, Sheppard L. Self-efficacy and clinical performance: a physiotherapy example. Adv Physiother. 2011;13(2):79-83.

51. Dalton M, Davidson M, Keating J. The assessment of physiotherapy practice (APP) is a valid measure of professional competence of physiotherapy students: a cross-sectional study with Rasch analysis. J Phys. 2011:57(4):239-46.

52. Roach KE, Frost JS, Francis NJ, Giles S, Nordrum JT, Delitto A. Validation of the revised physical therapist clinical performance instrument (PT CPI): version 2006. Phys Ther. 2012;92(3):416-28.

53. Jones $A$, Sheppard L. Use of a human patient simulator to improve physiotherapy cardiorespiratory clinical skills in undergraduate physiotherapy students: a randomised controlled trial. Internet J Allied Health Sci Pract. 2011;9(1):1-11.

54. Paparella-Pitzel S, Edmond S, DeCaro C. The use of standardized patients in physical therapist education programs. J Phys Ther Educ. 2009;23(2):15-23.

\section{Publisher's Note}

Springer Nature remains neutral with regard to jurisdictional claims in published maps and institutional affiliations.

Ready to submit your research? Choose BMC and benefit from:

- fast, convenient online submission

- thorough peer review by experienced researchers in your field

- rapid publication on acceptance

- support for research data, including large and complex data types

- gold Open Access which fosters wider collaboration and increased citations

- maximum visibility for your research: over $100 \mathrm{M}$ website views per year

At BMC, research is always in progress.

Learn more biomedcentral.com/submissions 